\title{
A toolkit for analyzing corporate cultural toolkits ${ }^{\text {is }}$
}

\author{
Klaus Weber* \\ Kellogg School of Management, Northwestern University, 2001 Sheridan Road, \\ Evanston, IL 60208-2001, USA
}

Available online 27 October 2005

\begin{abstract}
The cultural and discursive underpinning of industries and markets has received growing attention in recent years. I use Ann Swidler's conceptualization of culture as toolkit, and Pierre Bourdieu's concept of habitus as the starting point to further this enterprise. The article illustrates a strategy for measuring and comparing the cultural toolkits in use by different actors in a larger field. The strategy allows quantitative comparisons of similarity at the level of large comprehensive toolkits instead of selective elements or inferred deeper dimensions. It also takes into account the embeddedness of actors' cultural toolkits in the structures of larger social fields and the specificity of toolkits to communication contexts. While this analytic strategy is potentially applicable to any actor's toolkit in a recurring communication context, I use as an illustration the repertoires that different corporations in the pharmaceutical industry employ to account for their activities in their annual reports.
\end{abstract}

(C) 2005 Elsevier B.V. All rights reserved.

\section{Introduction}

The cultural and discursive underpinning of central industry and market processes has received renewed interest in recent years. One prominent approach in this area draws on a long tradition of comparative research, evoking "deep dimensions" of national cultures to explain differences in patterns of economic activity (Biggart and Guillén, 1999; Dobbin, 1994; Guillén, 1994). Note, however, that this approach locates culture in social and political formations outside the market or industry in question. Others have taken a different route and studied cultural aspects within general market and industry processes. This research generally focuses on specific aspects of culture, such as role of classification and categorization systems in processes of rivalry and valuation (Porac and Rosa, 1996; Zuckerman, 1999), the use of discourse in negotiating identities

\footnotetext{
is Paper prepared for Poetics special issue on culture and classification in markets.

* Tel.: +1 8474912201.

E-mail address: klausweber@northwestern.edu.
} 
and status orders (Bourdieu, 1993; White, 2000), or the cultural technologies for constructing value and reality (Abolafia and Kilduff, 1988; Fiss and Hirsch, 2005; Podolny and Hill-Popper, 2004). What is comparatively rare are approaches that locate culture inside an industry or market (as opposed to a nation) but analyze it in a comprehensive way (as opposed to focusing on specific selective elements). In this paper, I illustrate one approach for performing this third type of analysis, based on Ann Swidler's conceptualization of culture as a "toolkit" of means of action (Swidler, 1986, 2001a).

Swidler's toolkit view of culture bears some affinity to Lamont and Thévenot's (2000) notion of cultural repertoires, Bourdieu's (1990 [1980]) concepts of habitus and cultural capital, and other ideas associated with "theories of practice" (Schatzki et al., 2001). Put somewhat simplistically, the common denominator among these ideas is that culture influences action through more than values that provide the ends of action. Culture also supplies actors with the means - the tools - for solving practical problems and for navigating their environment. This "supply-side" analysis of culture shifts researchers' focus from values and choices to cultural resources, habits, skills and styles. As each actor has at hand only a bounded set of heterogeneous resources (concepts, actions, stories and symbols) for solving the diverse problems of everyday life, distinctive toolkits can be associated with particular actors and collectives. Bourdieu's concept of habitus is similar in that it links actors' limited set of cultural resources to their structural positions in a field of activity. A key difference is that the toolkit notion leaves more room for dissonance and situational improvisation in the deployment of cultural resources than the notion of habitus (Swidler, 2001b).

Despite the resonance and salience of the concept of repertoire in cultural sociology, empirical studies of comprehensive repertoires, cultural styles and habitus are at this point virtually absent in studies of markets and industries. This paper develops one strategy to analyze culture at the level of actors' comprehensive repertoires, instead of select cultural elements or deep cultural dimensions. The approach I propose seeks to do justice to the toolkit perspective's grounding in practice theory while creating opportunities for quantitative analysis in large-scale social settings, such as industries and markets.

The paper is structured as follows. I briefly review central terminology and some conceptual implications of the toolkit approach, then introduce the setting from which the empirical illustrations in this paper are drawn: the international pharmaceutical industry. The main part of the paper describes a four-step research process for analyzing cultural repertoires. I identify and discuss key decision points and tools along the way and use examples from the study as illustrations for analytic choices and the conclusions that can be drawn from such analysis.

\section{Conceptual issues in the study of cultural repertoires}

A central but often neglected aspect of the toolkit approach to cultural analysis is that cultural materials can be analyzed at the level of the repertoire, i.e., the entirety of cultural material at the disposal of individual actors or collectives. This contrasts with a more common focus, at least in economic sociology, on the diffusion of single concepts or changes in the dominance of a small number of competing "logics" (Fiss and Zajac, 2004; Scott et al., 2000; Thornton and Ocasio, 1999). One conceptual difference between a toolkit approach and the notion of logics is that there is no presumption that actors' toolkits are necessarily internally coherent or "systematic." If there is logical coherence in culture, it pertains to the level of grammar-like semiotic codes that constitute elements of a toolkit, but not to the more pragmatic assemblage of resources in the 
toolkit itself (Swidler, 2002). At the level of toolkits, the degree of organization is quite variable in time and space (Swidler, 1986, p. 278). In simpler terms, while the abstract cultural system that enables communication between actors may be very systematic and "logical," actors' toolkits are organized according to pragmatic principles. Actors can use several codes without being overly concerned about apparent inconsistencies. This difference between cultural system and repertoires is akin to the distinction between langue (language-system) and parole (speech) in semiotic theories of language (Saussure, 1959 [1915]).

A concern with comprehensive cultural resources "in-use" has implications for the study and dynamics of cultural repertoires. Actors use only a limited number of cultural elements routinely, because the correct use of new elements has to be learned and practiced. This implies that cultural elements that are candidates for adoption by an actor or a collective compete with existing toolkit elements. It is analytically useful to think of an actor's potential repertoire as an ecological space, with a carrying capacity for cultural material that is constrained by cognitive and social limits. New elements compete with the existing set, and hence processes, such as the learning or diffusion of specific concepts or practices in industries cannot be fully understood without an analysis of the existing toolkits that they compete with or blend in with. Associations or complementarities to existing repertoires facilitate learning, but learning may also necessitate partial forgetting or repressing of existing elements.

A second implication of the comprehensiveness of toolkits is that they can be analyzed not only in terms of their particular content, but also along more abstract dimensions, such as size, diversity, complexity, stability, complementarity and similarity. Such higher order attributes likely play a role in organizations' cultural competence in inter-organizational and market interactions, e.g., via mechanisms of requisite variety, skill and situational adaptativeness (Collins, 2004; Fligstein, 2001).

An organizations' repertoire-in-use is of course not only due to individual factors, such as learning and cognitive capacity. Social and cultural context plays a central role in shaping individual and collective actors' toolkits. One of Bourdieu's and other practice theorists' central contributions to the study of culture has been to articulate the connection between the use of culture (e.g., as tastes in cultural consumption) and the user's position in a larger social field, where fields are structured as a set of abstract positions that impose expectations of cultural expression on occupants (Bourdieu, 1993). Evidence of this correspondence can be found in the maintenance of status differences among market participants through the production or consumption of appropriate cultural materials (Bourdieu, 1984 [1979]; DiMaggio, 1987). Yet, non-hierarchical differences may equally be navigated through the use of cultural materials that serve as markers of identity and self (Lamont and Molnár, 2002; Swidler, 2001a).

Due to the embeddedness of cultural repertoires in the organization of larger fields, it is necessary to conceptually clarify the relation between toolkits of individual actors and the broader set of cultural resources at the field level. People know more culture than they (may) use. "Like a library that holds many more books than any one person could ever read, a "culture" sustains an array of resources that people can draw in different ways." (Swidler, 2002, p. 2). Socio-linguists draw a parallel distinction between a register (of a social field) and a vocabulary (of an actor). For the purpose of this essay, I will use the term cultural register to describe the set of cultural elements at the collective level of the field, and reserve the terms cultural toolkit and cultural repertoire for cultural resources at the actor-level. Toolkits are thus subsets of registers. 
Acknowledging the embeddedness of cultural resources in larger fields not only brings social structure into cultural analysis, but also highlights the context of different domains of action that define basic situational framings and that are subject to specific institutional norms (Goffman, 1974). For example, the cultural register in the domain of corporate management only partially overlaps with that of artistic consumption, social movement activism or participation in religious organizations. Competent actors recognize the norms of different interaction settings and behave accordingly (Eliasoph and Lichterman, 2003). Again, these actors may know more culture than they (can) use, but the use of cultural materials is bounded by the interaction setting as well as by social positions. Trespassing domains by borrowing from "foreign" registers requires great skill and is often negatively sanctioned (Fiss and Zajac, 2004).

The approach presented in this paper analyzes culture at the level of actors' toolkits in a particular domain and interaction setting. In the illustrative analyses, the domain is the management of corporations, and the interaction setting the public reporting of management to the organizations' stakeholders. The industry is the international pharmaceutical industry. Although for illustration purposes, I am only concerned with conceptual toolkits manifested in language, the analytic strategy generalizes to other aspects of culture, such as behaviors, material symbols and images. A central concern that drives the type of illustrative analyses presented is to assess the correspondence of companies' cultural repertoires and their positions in the industry.

\section{Empirical context for illustrations: corporations in the pharmaceutical industry}

I use data collected from pharmaceutical companies in Germany and the USA over a period of 20 years. This industry includes companies engaged in the development and production of prescription and over-the-counter drugs, diagnostics, generic drugs, and drug delivery services. The industry shows all characteristics of an institutionally recognized organizational field (DiMaggio and Powell, 1983, p. 143): Participants share a universal knowledge base (biochemistry and genetics), a societal task (improving human health), as well as goals (profit) and customers (the medical profession and healthcare delivery systems). Importantly, organizations orient their actions towards each other, showing awareness of interdependence and a common enterprise across national boundaries. The field has also been in existence for a long time and is recognized as an economic "sector" (Scott and Meyer, 1983) with interest groups, rankings, publications and regulatory agencies that span national boundaries.

Data for analyzing the field's cultural register and corporations' toolkits came from company's annual reports. Besides financial information, annual reports contain a free-format opening statement, often in the form of a "Letter to Shareholder (or Stakeholders)" and a "Management Discussion." These statements are collectively crafted by organizational leaders and communications experts to give an account of the past year and of future plans, on behalf of the corporation. It is important to note that the actor to which the cultural toolkits in those reports can be attributed is the company and not individual executives. The authors of the text explicitly speak on behalf of an abstract entity, not as their private selves.

The sample includes 94 companies (50 U.S., 44 German) with an average of 10 annual data points in the years between 1980 and 2001, resulting in 943 observations at the firm level (541 U.S., 402 German). Measurement points per firm range from 3 to 22 (mean =10.2), and measurement points per year range from 26 to 62 (mean $=44)$. This sample is the result of a "split design" approach (Firebaugh, 1997), which combines a panel component of repeated measures of the same companies with a survey component of changing companies over time. The panel component enables the assessment of changes in similarity between the same 
organizations. The survey component corrects for the fact that entry and exit processes change the overall composition of the industry after initial sampling. Both continuing members and new entrants contribute to the cultural register of the field, which makes this design desirable. The length of the analyzed statements ranged from about 20 to 110 sentences (5th-95th percentile).

\section{An analytic strategy}

A key challenge facing analysts of cultural toolkits is the complexity, diversity and relative unstructuredness of cultural resources, even when the setting is bounded by a particular field, actor type and communication domain. The issue surfaces at several stages of the process, e.g., in identifying the elements of a cultural toolkit in a comprehensive but parsimonious way, in meaningfully describing and representing the overall toolkit, and in reducing the richness of these data for higher-order analyses that permit conclusions about the relation between the use of cultural resources and locations in a field. The analytic process I describe and illustrate involves four steps: first, the identification of the elements that make up the field-level cultural register; second, the measurement and representation of cultural repertoires of individual actors; third, the representation of cultural similarity among corporations; and lastly, ways to map and statistically test the correspondence between cultural similarity and proximate field positions. For each process step, a general discussion of issues and decision points is followed by more selective illustrations from the study of corporate cultural repertoires.

The four-step process is similar to the one described by Mohr (1998) for measuring structures of meaning in a cultural system. The key differences are that (1) this essay is grounded in the analysis of cultural toolkits (pragmatic culture-in-use) rather than the analysis of cultural systems (deep logical structure of culture), and that (2) this essay places greater emphasis on semiotic and textual approaches for the identification of cultural elements and the ensuing task of reducing complexity and less on the generic techniques that can be applied once the data are simplified.

\subsection{Step 1: identifying the cultural elements in the field's register}

\subsubsection{The conceptual concreteness of cultural elements}

The very notion of "toolkit" or "repertoire" implies that cultural resources can be recognized as discrete and somehow stable elements. This necessary discreteness raises the conceptual question of what organizes culture into elements and the methodological question of how the discreteness of elements can be established empirically. Concepts and analytic procedures from semiotics and linguistics prove useful for both questions.

The conceptual issue is not trivial. Phenomenological and pragmatist traditions in social theory have long argued that human experience and activity is flux, a contourless flow of action and experience (Bergson, 1946 [1903]; Husserl, 1962 [1913]; James, 1890). In other words, "human action occurs as durée, a continuous flow of conduct, as does cognition. Purposive action is not composed of an aggregate or series of separate intentions, reasons and motives" (Giddens, 1984 , p. 3, emphasis added). If this is so, how can one speak of repertoires as comprised of discrete elements?

The solution is to clearly distinguish the extra-subjective cultural level from the subjective or inter-subjective personal level (Wiley, 1988). The extra-subjectivity of culture points to a semiotic view of culture, where signs and signification systems are shared and can be talked 
about independently of the subjective experience of actors. Cultural elements are then akin to semiotic signs, pairings of concepts (signified) and sign-vehicles (signifiers, such as words). Semioticians see signs as concrete by nature (Eco, 1976; Peirce, 1955 [1898]; Saussure, 1959 [1915]). ${ }^{1}$ The semiotic systems that underlie signs punctuate the singular durée of subjective experience as soon as experience is reflected and talked about. It then becomes possible to talk of experiences, actions, and repertoires in the plural. Giddens $(1984$, p. 3) accordingly states that " "acts" are constituted only by a discursive moment of attention to the durée of lived-through experience." And Weick (1995, p. 25) makes a similar point when he emphasizes how sense is made by retrospectively "extracting cues" from what has already happened. The concreteness of cultural repertoires is a direct consequence of culture involving non-private signification rather than private experience.

In sum, cultural repertoires are made up of concrete symbolic resources that are organized into recognizable sets. Note that this leaves out "non-cultural" resources, such as purely individualsubjective and unarticulated experiences and imaginations. Because cultural toolkits by definition can be articulated, it seems natural to study repertoires used in communication (Swidler, 2001a).

\subsubsection{Methodological approaches for establishing the concreteness of elements}

The actual dimensions of distinction and association in an abstract semiotic system can of course only be inferred from empirical observations of the use of cultural elements. Much of this process relies on the researcher's skill and understanding of the setting. However, some qualitative semiotic techniques can help structure the process and increase the confidence that the cultural elements found are discrete and mutually distinctive. Paradigmatic clustering, commutation tests and semiotic square analyses are particularly applicable.

Paradigmatic clustering (Barthes, 1967 [1964]; Chandler, n.d.; Feldman, 1995, pp. 22-30) exploits the idea of what semioticians call "paradigms," larger cultural structures that evoke distinctive institutional concerns. Minimal cultural elements, such as words, can be grouped with others if they act as signifiers of the same paradigm. Distinctiveness of cultural elements is thus established by relating signs that are part of an expression (e.g., a text) to connotations outside that expression. Elements within the cluster are substitutes and only one of them can be used in any particular instance (Barthes, 1967 [1964]; Eco, 1976). For example, notions of what corporations are and how they should be managed (the paradigmatic context) organize the cultural repertoire for talking about corporations (the cultural elements in communications). A useful way to identify paradigmatic distinctions is through images and "root metaphors" that relate signs to broader domains (Barthes, 1967 [1964]; Putnam and Fairhurst, 2000). For example, an organization can be seen as a production system (machine metaphor) or as a set of property rights (contractarian metaphor). Within each category multiple signifiers (terms, concepts) express that cultural logic. Paradigmatic clustering therefore also ensures that cultural

\footnotetext{
${ }^{1}$ This discussion draws primarily on the "structuralist" strand of semiotics, commonly associated with the foundational work of Ferdinand de Saussure. For the purpose of the present analyses, structural semiotics proposes a relatively reliable correspondence between signifier (e.g., words) and signified (the concept, meaning) and an extra-subjective system of distinctions and simile that differentiate signs (signifier-signified pairings). Simplistically speaking, poststructuralists doubt both the reliability of correspondence and the extra-subjectivity of the distinctions. Debates between these camps are lengthy and at times fierce. My own approach is more pragmatic than ontological: Structural analysis provides an attractive set of tools for the kind of analysis I am concerned with in this paper. The cultural world is of course not perfectly structured so that conceptual and empirical imprecisions can be reduced through careful analysis but must be tolerated at some level.
} 
elements are identified at the level of cultural concepts (signified) and not words or symbols (signifiers).

Commutation tests (Barthes, 1967 [1964]) are disciplined thought experiments that establish the distinctiveness of cultural elements through reference to other elements within the same expression (e.g., within a slice of communication). The researcher tests whether one phrase or concept can be substituted for another without fundamentally changing the meaning of the original sentence or statement. For example, take the simple sentence "We intend to divest the subsidiary to focus on our core business." It is possible to substitute the phrase "sell the business unit" for "divest the subsidiary" without changing the meaning of a sentence. Substituting "acquire a company" changes the meaning of the sentence. Substitutable concepts and phrases form a category. The same procedure can also be used at the more abstract level of connotations identified through paradigmatic clustering. Both selling and acquiring companies connote a view of corporations as a portfolio of businesses that are being bought and sold. An alternative connotation is more organismic, seeing corporations as dynamic wholes. At this level, the three phrases above are substitutable in that they evoke the same connotation. The phrase "invest in our capabilities," by contrast, evokes a different connotation and forms a distinct category.

The semiotic square (Greimas, 1987) is a tool to check the cultural elements found thus far for logical completeness and consistency. It is particularly useful for identifying "absences," cultural elements that are implicit but rarely directly observed because they carry a negative valence. Starting with one cultural concept, the square maps logical conjunctions and disjunctions so that paired concepts can be analyzed more completely and the underlying binary distinctions of a symbolic system be exploited more fully. Fig. 1 shows the basic structure of a semiotic square with an example from the analysis of corporate registers.

The horizontal axes show relations of contrariety, or oppositions. The upper horizontal relationship specifies the primary relationship ("presence"), the lower an implied secondary ("absence"). The vertical axes indicate complementarities, i.e., concepts that are can coexist although they are not identical. The diagonals show contradictions, pairs of concepts that cannot logically describe something at the same time. In the analysis of corporate cultural toolkits, "goals" is a frequent category used by corporations to describe their aspirations. The opposition is "journey," which is used less frequently and can be seen as a negation anchored on the primary assertion ("the journey is the goal"). The remaining parts of the square identify more subtle concepts aligned with the upper-half opposition ("standstill" and "aimless"). It depends on the

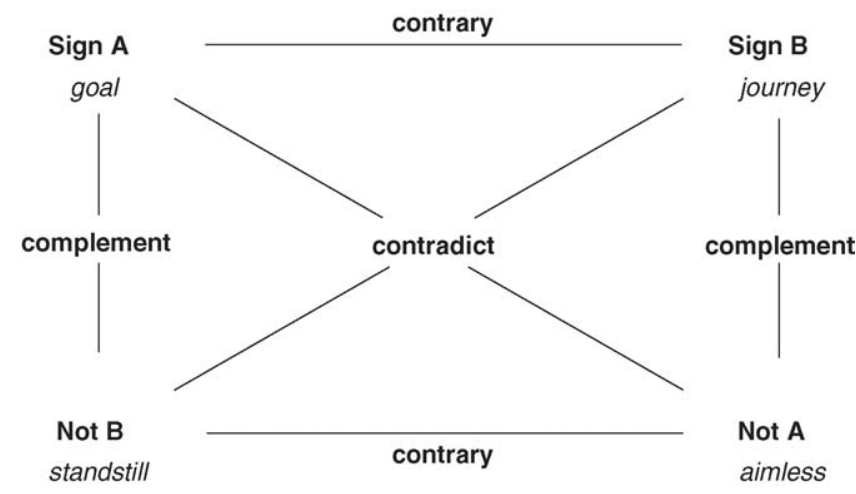

Fig. 1. Example of a semiotic square analysis. 
interest of the researcher whether to explicitly code for "absences," only look at manifest cultural elements, or subsume absences under the complementary primary category.

\subsubsection{Operational issues in extracting cultural concepts from textual data}

Language provides a good way to assess actors' cultural repertoires (Swidler, 1986, p. 273, 2001a). For the analyst that uses textual data to analyze cultural toolkits, it is useful to think of language not only as data, but also as a metaphor of culture. Cultural elements can be seen as parallel to words or phrases, toolkits and registers parallel to vocabularies, cultural scripts parallel to syntax, action strategies parallel to sentences, and fields parallel to discourses. With this in mind, general approaches to textual analysis can be evaluated in terms of how well they match the conceptual framework of culture as toolkit. Carley (1993) and Roberts (2000) distinguish four major approaches to textual analysis: content analysis, semantic analysis, narrative analysis, and discourse analysis. ${ }^{2}$

4.1.3.1. Type of textual analysis. Content analysis deals with categories of elements in a text, where each element is looked at in isolation without attention to its immediate context of other concepts. ${ }^{3}$ Within content analysis, lexical morphology examines the smallest unit of signifiers in a text, i.e., single words. Conventional content analysis is broader in that it looks at words or larger phrases, but often categorizes them according to the signified, i.e., the concepts that these words refer to. Semantic analysis examines how basic units of text are positioned within a larger text. Semantic analysis combines the analysis of categories (content analysis) with a focus on the grammatical or associational relationships between the concepts (Carley, 1993, p. 93; Roberts, 2000). Semantic analysis is often concerned with implicit maps or concept-networks (Bearman and Stovel, 2000; Carley, 1997). While content-analytic and semantic approaches focus on small textual units, the third approach, narrative analysis, puts the entire text center stage. Narrative analysis is concerned with the turns and plots that put together a story (Czarniawska, 1998; Franzosi, 1998; Greimas, 1987). Finally, discourse analysis is concerned with multi-text formations that reflect broad regimes of interpretation. Discourse analysis emphasizes the social and ideological underpinning of language practices over the technical aspects of meaningmaking (Foucault, 1972).

For analyzing cultural repertoires, content analysis is a straightforward approach to identify the elements that make up a toolkit, especially in combination with semiotic techniques for identifying categories with a common cultural connotation. The toolkit imagery suggests that elements of a repertoire can be combined relatively freely through bricolage (Levi-Strauss, 1966 [1962]; Swidler, 2001a). The existence of combination rules (scripts, grammar, narrative tropes) can then be examined as an empirical and theoretical question, based on the foundation laid by content coding. The broader discursive context of the focal text is of course important for understanding the meaning of words and for developing categories that are generalizable.

\footnotetext{
2 I use the term "textual analysis" in a broad sense, including not only written documents but also spoken communication and other formations. A critical feature of texts for the study of cultural repertoires is that they express communication repertoires and choices of an author. Surveys or predefined forms and tables, for example, are not textlike while answers to interview questions are.

${ }^{3}$ I use the term "content analysis" in a narrow methodological sense here. In practice, of course, researchers often establish categories as a (necessary) first step in textual analysis, to be followed by analyses of associations, such as cooccurrences.
} 
4.1.3.2. Development of category schemes. Within content analysis, a key choice concerns the use of custom or standard categories. Several general-purpose category schemes have been developed, such as the Harvard Psychological Dictionary or Lasswell's Value Dictionary (Lasswell and Leiters, 1949; Namenwirth and Weber, 1987). Some standard category schemes have the advantage of having been previously validated with different text corpuses (examples categories from Lasswell include "religion," "self," "audience"). However, there are several drawbacks that make standard category schemes and dictionaries of limited use for studying repertoires. First, the categories are usually quite broad and lack the precision for analyzing a peculiar genre, such as corporate language. For example, some categories may have been further elaborated in a context, e.g., "audience" into "shareholders," "other stakeholders" and "the general public." Second, it is less likely that different words (signifiers) are reliably associated with a cultural category (signified) across discursive contexts. For example, the word "equity" signifies a different category in a corporate setting than in a legal one. Third, if the goal is an analysis of comprehensive repertoires, standard schemes are likely to only represent a subset of the pertinent cultural elements. It is therefore generally desirable to develop deductive categories from a sample of the analyzed discourse, or at least to check pre-existing category schemes for applicability and completeness.

4.1.3.3. Coding units. For coding the presence of cultural elements in documents, the text unit to which codes are assigned needs to be specified. This choice is consequential because it determines the ability to perform subsequent semantic analyses and the level of (dis-) aggregation at which data can be analyzed. For example, it may be more informative to know that two categories are often used in the same sentence than that they are used in the same document. While it would be possible to use individual words or entire documents as coding units, sentences or paragraphs are perhaps more meaningful units for the analysis of cultural toolkits in texts. A sentence forms the smallest syntactically closed unit in naturally occurring language and is often the obvious unit in communication (Krippendorff, 2003). The choice depends, however, on the researcher's interest in analyzing relationships between cultural elements, and on the breadth of the cultural categories used. Both factors are specific to research questions and designs.

\subsubsection{Temporal issues and cultural change}

For cross-sectional studies of cultural toolkits, a snapshot of the current cultural register is sufficient. In the example study, however, I used data over a 21-year period. Changes in cultural elements are often of interest to researchers. From a semiotic perspective, cultural change may take several forms: the addition and deletion of cultural elements from actors' toolkits (described here); changes in the structure of the semiotic system, e.g., the elaboration or simplification of distinctions (Levi-Strauss, 1974); or changes in the relation among elements and between signifiers and signified, e.g., in the process of concept formation or the subversion of meaning (Somers, 1994). In the present study, only changes through adding and deleting elements were of interest. Hence, I constructed a coding scheme of concepts that was robust enough to cover the entire period, conceding some corresponding slippage in precision because subtle changes in meaning were not recorded.

\subsubsection{Illustration: elements of corporate cultural repertoires in the pharmaceutical industry}

In the study of corporate cultural repertoires in the pharmaceutical industry, I entered the process of element identification with a broad analytic framework derived from the sensemaking 
literature (Gioia and Thomas, 1996; Thomas et al., 1993; Weick, 1995). Sensemaking processes involve at least three central aspects: perceptions, interpretations and actions.

I used a structured inductive process to identify the elements that make up the collective cultural register of this field. Initially sampling 10 documents that reflected a cross-section of countries, years and companies, I developed categories according to the process described below. I then added another 10 documents to revise, simplify and complete the category scheme. In the 4th iterations (50 documents), no further modifications were indicated and I decided that the coding scheme had reached saturation. To verify this conclusion, I asked a second researcher to check for additional categories in a sample of 10 documents.

In each iteration, I first read all documents, identifying and recording words and phrases that referred to perceptions, interpretations and actions. I then looked for initial groupings of words and phrases into categories using commutation tests and paradigmatic clustering as described above. Note that commutation tests can be applied to phrases (signifiers) but also in turn to the broader connotative categories from paradigmatic clustering (signifieds). After having arrived at a preliminary set of categories, I looked for higher order groupings, where categories referred to the same aspect of sensemaking. For example, interpretations involve evaluations that relate what was observed to the self, such as "positive," "important," "negative." But interpretations also put the observed in a temporal context, such as seeing a process unfolding as "continuous," "cyclical," or "accelerating." Commutation tests on the first-order categories can again be used to identify groupings and mutually exclusive categories within groupings. Connotative categories should be mutually exclusive within, but need not be so across these groupings. I reserved the semiotic square analysis for a final check for completeness and logical consistency because I was interested more in presences than absences of cultural elements in the documents I analyzed.

By the time saturation had been reached, the register of cultural elements contained 6 groupings, 35 pairs of logical oppositions and 63 empirically observable cultural elements, which together account for most of the commonly used cultural elements employed in the annual reports of these companies. Table 1 shows the categories, with example phrases and short descriptions of their connotations.

The cluster "environmental domains" contains a set of environmental dimensions that receive attention. Categories in this cluster include, for example, product and capital markets, the medical profession, technology and geographic areas. Domains divide up the world into conceptually distinct spheres, each governed by its own rules and causalities. The connotative meaning of different domains suggest the rules and causalities under which corporations operate and defines a conceptual space in which firms can locate themselves compared to others. For example, product markets are governed by competitive market mechanisms and allow the company to position itself as a cost leader, while the medical profession is governed by a desire to improve human health and allows the company to position itself as a contributor to human welfare. I identified 10 empirical categories, which in part overlap with environmental dimensions used in extant literature (Dess and Beard, 1984; Porter, 1980; Sutcliffe and Huber, 1998). However, observed categories do not map onto existing synthetic frameworks.

The cluster "evaluation" contains a set of concepts that relate a piece of information to the company's identity and interests, shifting the perspective from "objective" to "subjective." Categories in this cluster include evaluations of importance, certainty and positiveness. Evaluations appraise what an observation means for the self or for some moral standard (Dewey, 1939). This frames the situation in which the organization sees itself and what action may be required. The categories found again include dimensions identified in the extant literature (e.g., 
Table 1

Cultural register: categories, groupings and connotations

\begin{tabular}{|c|c|c|c|c|}
\hline $\mathrm{d} \#$ & Dimension & $\mathrm{c} \#$ & Category & Connotation \\
\hline \multicolumn{5}{|l|}{ Attention } \\
\hline \multicolumn{5}{|c|}{ Environmental domain } \\
\hline \multirow[t]{2}{*}{001} & System & 001 & Macro-economy & Company as part of an economic system \\
\hline & & 002 & Society & Company as part of a social system \\
\hline \multirow[t]{2}{*}{002} & Community & 003 & Product market & Community defined by market rivalry \\
\hline & & 004 & Business partners & Community defined by exchange relations \\
\hline \multirow[t]{2}{*}{003} & Stakeholders & 005 & Labor market & Company as an employment provider \\
\hline & & 006 & Capital market & Company as investment vehicle (private enterprise) \\
\hline \multirow[t]{2}{*}{004} & Supply chain & 007 & Medical & Company delivers human health \\
\hline & & 008 & Technology & Company uses technological knowledge \\
\hline \multirow[t]{2}{*}{005} & Location & 009 & Geographical & Company as situated by locale \\
\hline & & 010 & State & Company as situated by citizenship \\
\hline
\end{tabular}

Interpretation

Evaluation

\begin{tabular}{llll}
006 & Salience & $\begin{array}{l}011 \\
-^{\mathrm{a}} \\
007\end{array}$ & $\begin{array}{l}\text { Important } \\
\text { Incidental }\end{array}$ \\
& Closure & 012 & Certain \\
013 & Ambiguous \\
008 & Valence & 014 & Positive \\
& & 015 & Negative \\
009 & \multirow{2}{*}{ Magnetism } & 016 & Attractive \\
& & 017 & Repellant \\
010 & Utility & 018 & Helpful \\
& & 019 & Impeding
\end{tabular}

Temporal trends

$\begin{array}{llll}011 & \text { Monotony } & 020 & \text { Continuous } \\ 011 & & 021 & \text { Novel } \\ 012 & \text { Vertical } & 022 & \text { Rise } \\ 012 & & 023 & \text { Fall } \\ 013 & \text { Repetition } & 024 & \text { Cyclical } \\ 013 & & { }^{\text {b }} & \text { Directed } \\ 014 & \text { Pace } & 025 & \text { Accelerate } \\ 014 & & 026 & \text { Slow down }\end{array}$

Aspirations

$\begin{array}{llll}015 & \text { Comparative } & 027 & \text { Exception } \\ & & 028 & \text { Normal } \\ 016 & \text { Historical } & \begin{array}{c}029 \\ -^{\mathrm{a}}\end{array} & \text { Improve } \\ & & \text { Destruct } \\ 017 & \text { Dependence } & 030 & \text { Service } \\ & & 031 & \text { Independence } \\ 018 & \text { Future } & 032 & \text { Vision } \\ & & 033 & \text { Tradition } \\ 019 & \text { Ends } & 034 & \text { Goal } \\ & & 035 & \text { Journey }\end{array}$

Action

Means of action

020 People

036 Select people

Stands out, deserves attention

Not worth attention

Implication is known, facts

Implication is equivocal, uncertain

Valued as positive to self or morality

Valued as negative to self or morality

Desire to move towards realization

Desire to move way from/avoid realization

Assists own projects and interests

Hinders own projects and interests

Future is continuation of past, stable and long-lived

Future is a break from the past

Movement towards a higher quality

Movement towards a lower quality

Movement oscillates, repeats itself

Movement has direction

Continuation of direction, but increasing pace

Continuation of direction, but decreasing pace

Perform outside existing comparisons

Perform within comparison to others

Seek to perform better than own past

Seek to perform worse than own past

Authority delegated by stakeholders

Authority vested in self

Guided by a desired future

Guided by a valued past

Achievement in a plan-act-evaluate sequence

Achievement in ongoing process of becoming

Organization as a system of job positions to be filled 
Table 1 (Continued)

\begin{tabular}{|c|c|c|c|c|}
\hline $\mathrm{d} \#$ & Dimension & $\mathrm{c} \#$ & Category & Connotation \\
\hline & & 037 & Develop people & $\begin{array}{l}\text { Organization as an assembly of individuals } \\
\text { to be improved }\end{array}$ \\
\hline \multirow[t]{2}{*}{021} & Organization & 038 & $\begin{array}{l}\text { Optimize } \\
\text { organization }\end{array}$ & $\begin{array}{l}\text { Corporation as a designed organism, mange } \\
\text { within structure }\end{array}$ \\
\hline & & 039 & $\begin{array}{l}\text { Restructure } \\
\text { organization }\end{array}$ & $\begin{array}{l}\text { Corporation as designed organism, mange } \\
\text { structure itself }\end{array}$ \\
\hline \multirow[t]{2}{*}{022} & Scale & 040 & Build capacity & $\begin{array}{l}\text { Corporation asathroughput system, improve } \\
\text { by growth }\end{array}$ \\
\hline & & 041 & Downsize & $\begin{array}{l}\text { Corporation as a throughput system, improve } \\
\text { by down }\end{array}$ \\
\hline \multirow[t]{2}{*}{023} & Bus scope & 042 & Diversify business & $\begin{array}{l}\text { Corporation as an entity to spread risk, } \\
\text { realize synergies }\end{array}$ \\
\hline & & 043 & Focus business & $\begin{array}{l}\text { Corporation as an entity with an singular, } \\
\text { core identity }\end{array}$ \\
\hline \multirow[t]{2}{*}{024} & Money & 044 & Invest money & $\begin{array}{l}\text { Corporation as a financial vehicle, manage } \\
\text { input side }\end{array}$ \\
\hline & & $-^{c}$ & Earn money & $\begin{array}{l}\text { Corporation as a financial vehicle, manage } \\
\text { output side }\end{array}$ \\
\hline \multirow[t]{2}{*}{025} & Product & 045 & Develop product & $\begin{array}{l}\text { Corporation as a product portfolio, } \\
\text { manage innovation }\end{array}$ \\
\hline & & 046 & Sell product & $\begin{array}{l}\text { Corporation as a product portfolio, } \\
\text { manage marketing }\end{array}$ \\
\hline \multirow[t]{2}{*}{026} & $\begin{array}{l}\text { Market } \\
\text { position }\end{array}$ & 047 & Strengthen position & $\begin{array}{l}\text { Corporation as a market player, improve } \\
\text { by increasing market power }\end{array}$ \\
\hline & & $-{ }^{\mathrm{a}}$ & Reduce position & $\begin{array}{l}\text { Corporation as a market player, } \\
\text { improve by reducing market power }\end{array}$ \\
\hline \multirow[t]{2}{*}{027} & Geo scope & 048 & Expand geo scope & $\begin{array}{l}\text { Corporation as a global actor, improve } \\
\text { by extending presence }\end{array}$ \\
\hline & & $-{ }^{\mathrm{a}}$ & Contract geo scope & $\begin{array}{l}\text { Corporation as a global actor, improve } \\
\text { by reducing presence }\end{array}$ \\
\hline \multirow[t]{2}{*}{028} & Collaboration & 049 & Enter alliance & $\begin{array}{l}\text { Corporation as part of an industrial network, } \\
\text { seek centrality/cohesion }\end{array}$ \\
\hline & & $-{ }^{\mathrm{a}}$ & Exit alliance & $\begin{array}{l}\text { Corporation as part of an industrial network, } \\
\text { seek isolation }\end{array}$ \\
\hline \multirow[t]{2}{*}{029} & Business units & 050 & Acquire & $\begin{array}{l}\text { Corporation as a portfolio of businesses, } \\
\text { improve by buying }\end{array}$ \\
\hline & & 051 & Divest & $\begin{array}{l}\text { Corporation as a portfolio of businesses, } \\
\text { improve by selling }\end{array}$ \\
\hline \multicolumn{5}{|c|}{ Style of action } \\
\hline \multirow[t]{2}{*}{030} & Obligation & 052 & Assertive & $\begin{array}{l}\text { Competent action as serving own interests } \\
\text { and values }\end{array}$ \\
\hline & & 053 & Responsible & $\begin{array}{l}\text { Competent action as stewardship for external } \\
\text { interests and values }\end{array}$ \\
\hline \multirow[t]{2}{*}{031} & Emotion & 054 & Rational & $\begin{array}{l}\text { Competent action applies norms of } \\
\text { (instrumental) rationality }\end{array}$ \\
\hline & & 055 & Emotional & $\begin{array}{l}\text { Competent action is driven by passion and } \\
\text { emotional involvement }\end{array}$ \\
\hline \multirow[t]{2}{*}{032} & Energy & 056 & Efficient & $\begin{array}{l}\text { Competent action achieves ends with } \\
\text { minimal energy }\end{array}$ \\
\hline & & 057 & Effortful & $\begin{array}{l}\text { Competent action expends high energy } \\
\text { without concern } \\
\text { for return }\end{array}$ \\
\hline 033 & Longevity & 058 & Decisive & Competent action swiftly seizes opportunities \\
\hline
\end{tabular}


Table 1 (Continued)

\begin{tabular}{lllll}
\hline $\mathrm{d} \#$ & Dimension & c\# & Category & Connotation \\
\hline \multirow{2}{*}{034} & \multirow{2}{*}{ Risk } & 059 & Committed & Competent action sustains a course over longer time \\
& & 060 & Bold & Competent action takes risks \\
\multirow{2}{*}{035} & \multirow{2}{*}{ Enactiveness } & 061 & Careful & Competent action analyzes and avoids unnecessary risks \\
& & 063 & Venturing & Competent action creates opportunities through action \\
& & & Competent action creates opportunities through learning
\end{tabular}

a Not observed frequently enough to warrant coding.

${ }^{\mathrm{b}}$ Direction is implied in rise, fall, continuation categories; therefore, no separate category.

${ }^{c}$ Earning money is reported frequently in annual reports, but rarely treated as an action.

the threat-opportunity strategic framings identified by Dutton and Jackson, 1987), but are more comprehensive as a set.

The cluster "temporal trends" contains framings of temporal developments, which are the basis of extrapolating observations and evaluations to the future, and of forming expectations. For example, a negative situation due to a poor economy can be seen as part of a cyclical ebb and flow of the business cycle, or as part of a continued state of economic weakness. The temporal framing prompts different expectations and actions. The temporal framing also suggests whether or not past experience is of value for future action. Zerubavel (2003) eloquently demonstrates how collective representations of similar temporal patterns in history bind together communities and influence their actions.

The cluster "aspirations" contains framings used to direct and assess organizational performance. Categories include, for example, reaching goals, comparisons with peers, and serving stakeholders. Aspirations are internal sources of how situations are framed. They prompt actions to perform according to the chosen standard.

The cluster "means of action" contains a set of concrete corporate strategic actions that can be used in the pursuit of aspirations, in response to evaluation, and in the light of temporal trends. Action strategies describe how a company can act on its environment. Examples are organizational restructuring, developing new products, geographic expansion, and alliances. Types of action strategies connote ideas about the nature of corporations and how they are competently managed. The concept of strategic repertoires has been used in strategy research, although with more technical categories without reference to their connotative meanings (Chen, 1996; Miller and Chen, 1996).

The cluster "action styles" contains attributes used to describe the style of competent management. Categories include being rational, committed, careful or decisive. By describing appropriate styles, these categories again evoke connotations about the norms and rules of conduct that should govern corporate management.

\subsection{Step 2: measurement and representation of individual actors' cultural repertoires}

\subsubsection{Identification and representation of actor repertoires}

Actors' repertoires can fundamentally be seen as subsets or selections from the cultural elements available in the larger field. ${ }^{4}$ Individual actors either use or do not use a particular

\footnotetext{
${ }^{4}$ I use "selection" and "choices" in this discussion to emphasize the discreteness of the difference, not to suggest that actors are unconstrained in their agency to use particular cultural elements (see the earlier discussion of external and internal constraint).
} 
element in constructing their courses of action. The distinctiveness of their toolkit derives from the configuration of elements in use. However, the habitual basis of selections of cultural resources and the diversity of pragmatic problems to which they are applied suggest that differences between actors arise not only from binary choices to include a cultural element or not, but also from the emphasis, pervasiveness and centrality with which different elements are used. Accordingly, Swidler (2002, p. 2, emphasis added) suggests that "differences between two national cultures [or two actors] are best seen as different emphases and selections from repertoires with many overlapping possibilities." Difference at the actor level thus derives from two factors: the routine use of only a limited subset of the cultural elements available in the larger field, and the emphasis with which elements are used.

Effective ways for capturing the concept of "emphasis" hinges on the research setting and question. The sequence with which elements are evoked in a story may provide cues to their importance if there are strong norms regarding plot structures (Abbott, 1995). For example, in many academic journal genres, central theoretical framings are articulated in the beginning. In settings without strong norms for combining cultural elements, the position of elements relative to others, e.g., in terms of associative centrality, and an element's frequency of use are robust measures of emphasis. In observing spoken language, contextual cues, such as body language and tone of voice, may provide additional information.

\subsubsection{Key properties and dimensions of repertoires}

Selections and emphases are not random, but reflect social processes that create differences in status, position and identity among participants in a field. Cultural toolkits differ not only in the inclusion of and emphasis on particular elements, but also along second order properties. Dimensions, such as repertoire size, diversity, balance and stability can serve as further sources of difference and are often of substantive interest to researchers. For example, Peterson and Kern (1996) argue that elite status in U.S. society was traditionally associated with a small repertoire of "high arts" appreciation activities but is increasingly associated with a broad repertoire of "omnivorous cultural consumption." Bourdieu's model of cultural change suggests that highstatus "avant-garde" producers of culture necessarily need more dynamic repertoires of styles than low-brow producers (Gartman, 2002). And Weick $(1979,1996)$ evokes the idea of requisite variety to suggest that the optimal breadth of cultural toolkits depends on the diversity of problems posed by the environment.

For analysts of culture, the challenge of complexity returns in the identification and representation of individual toolkits. In contrast to the analysis of systems of meanings, which are expected to be organized by some deep structural dimensions that allow for simplified representations (Mohr, 1998), the pragmatic and heterogeneous nature of cultural toolkits makes reductions in dimensionality harder. In the example of corporations in the pharmaceutical industry, an individual corporation could potentially use all 63 categories identified at the field level, with varying emphasis placed on them at different times. Importantly, there is no expectation that these 63 dimensions are organized by a small number of underlying dimensions.

Analyses of entire repertoires can thus become taxing, both in terms of extracting and processing the data and in terms of communicating the results in a systematic yet intuitively understandable way. Sixty-three-dimensional systems are hard to comprehend. Quantitative algorithms and abstractions, such as parameters of size, diversity and stability can help with the simplification, as can quantitative and statistical techniques for data reduction (Mohr, 1998). An additional and often effective way of letting intuitive understanding keep step with quantitative 
sophistication is the use of graphical representations of single or aggregate repertoires. In the following two sub-sections, I illustrate these general strategies with some selective examples from the study of corporate cultural repertoires.

\subsubsection{Illustration: quantitative text analysis for measuring corporations' toolkits}

To identify the cultural elements used by corporations in the pharmaceutical industry, I coded the entire text corpus of annual reports using computer-automated content analysis. The coding scheme was equivalent to the cultural register identified in the previous step. In computerized content analysis, the researcher defines a dictionary of phrases that indicate the presence of a coding category. A text search and retrieval program then detects instances of those words from the text and assigns codes (see Evans, 1996; West, 2001, for overviews).

Computer-automated content analysis has two advantages: cost and speed of coding a large body of text, and the absence of "coder drift," a common problem with manual coding. Automated coding has drawbacks that make it of lesser use for some research questions. Human coders more easily detect implicit and ambiguous meanings that are not imbedded in the manifest words in the text (Carley, 1993). Hence, for researchers that are interested in "absences" and more complex cultural content, and for researchers that analyze a genre with few conventions and very broad repertoires, automation is difficult. Computerized coding dictionaries are also difficult to calibrate for comparative studies, e.g., when novels and scientific books are coded for the same categories. In the present case, automation was possible because the study deals with a single genre with a relatively formulaic language and limited cross-national differences at the concept level. Even in this case, it is desirable to assess the degree of unavoidable slippage between "intelligent" human coding and "dumb" automation. This can be achieved by computing the inter-coder reliability between human and computer coding on a sample of text.

A first step was to develop English and German coding dictionaries (key phrase lists) for each coding category. I first compiled an initial key phrase list using phrases recorded in identifying the field register, thesauruses, forward and back translations to calibrate and expand the English and German versions, and word frequency lists created from the entire corpus, in which I examined the 2000 most common words in each language for words missing in the previous lists.

In a second step, I tested this list on a sample of 10 documents in each language. I subsequently examined the coded documents and modified the dictionary accordingly. To determine the quality of the dictionary at this stage, I coded the same documents myself and calculated a "hit rate" as the percentage of sentences coded correctly by the computer, and a "false hit" rate as the percentage of sentences coded erroneously by the computer. The third step was then to repeat step 2 until the hit rate was at least $80 \%$ and the "false hit" rate smaller than $10 \%$. The same technique was used, e.g., by Wade et al. (1997) and Porac et al. (1999). These levels were reached after three iterations for all but four of the categories.

After running the content analysis program on all documents, I created a measure of the relative emphasis for each repertoire element. The measure of emphasis is the pervasiveness with which an element was used throughout a document. A cultural element used in every single sentence is emphasized more than one that occurs in only one. The emphasis score is the number of sentences in which a category occurred, divided by the number of sentences coded as 1 ("hit") for all categories in the cluster. This approach corrects not only for the length of the document, but also for its "coding density." For example, if the category "technology" were one out of a total of 10 codes assigned in a document, it carries more weight than were it one out of 50 . Standardization was by cluster "hits" rather than the document total because categories are 
assumed to be alternatives only within, not between clusters. The formula for calculating the emphasis measure is:

$$
E_{n}=\frac{\sum_{m} c_{n}}{\sum_{n} \sum_{m} c_{n}}
$$

where $m$ is the number of coding units (sentences) in the document, and $n$ the number of categories within a grouping of categories.

To establish the reliability of this coding, a subset of sentences was also coded by a research assistant, and another subset of documents that were available in both English and German were computer-coded in both languages. I used Krippendorf's alpha to assess human-computer and inter-language reliability. Krippendorf's alpha is a generalization of several reliability indices. The metric can be applied to any number of observers, measurement metric, sample size, and data completeness level (Krippendorff, 2003). For the binary coding used here, alpha is defined as:

$$
\alpha_{\text {binary }}=1-\frac{D_{\mathrm{o}}}{D_{\mathrm{e}}}=\frac{(n-1) o_{01}}{n_{0} n_{1}}
$$

where the observed disagreement $D_{\mathrm{o}}$ equals the total units coded by both coders $(n)$ times the discrepant units $\left(o_{01}\right)$, and the expected disagreement $D_{\mathrm{e}}$ is the product of the total number of units coded as zero $\left(n_{0}\right)$ and one $\left(n_{1}\right)$ by both coders combined. Thus, $\alpha$ takes into account chance agreement and sample size. The category reliabilities were generally satisfactory (mean humancomputer $\alpha=0.76$, range $0.54-0.92$, mean inter-language $\alpha=0.88$, range $0.70-0.99$ ).

The analytic path described here, moving towards an assessment of the relative prevalence of different elements in an actor's toolkit-in-use, is of course only one direction to take. In the course of reducing the complexity and richness of the data, some information gets lost. For example, relationships between elements and their positioning in cultural accounts can no longer be analyzed after the aggregation process that lead to the calculation of emphasis metrics. Methodologies, such as sequence analysis (Abbott, 1995) or network-based formal analyses of function and narrative structure (Bearman and Stovel, 2000; Carley, 1997; Mohr, 1998) provide alternative paths.

\subsubsection{Illustration: graphical representation of repertoires}

To illustrate the intuition behind differences in repertoires, Fig. 2 maps average profiles of U.S. and German firms' repertoire usage in 1980 and 2001. The figure uses averages of collectives to smooth differences due to the non-use of categories by specific companies. The same mapping of emphasis profiles can, however, also be created for companies over repeated observations or other groupings that correspond to positional or identity differences in the field under study. The figure shows cultural elements for representing actions.

The graphs in Fig. 2 contain three pieces of information. The relative emphasis on alternative cultural elements by the same actor type in the form of a profile is shown in the shape of the graph. The comparison of two profiles in terms of similar emphases is shown in the degree of overlap between the two shapes in the same graph. And the direction of change in emphasis in both groups can be gauged from a comparison of the graphs in each horizontal panel. Fig. 2 suggests that on average, German and U.S. firms placed different emphasis on different dimensions. These differences were smaller in 2001 than in 1980. For example, the bottom two charts show that in 1980, U.S. corporations emphasized cultural elements that represented their actions as efficient, 
Means of action: 1980

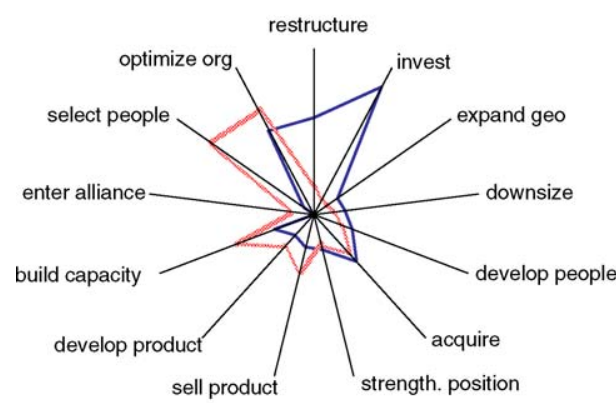

口DE 1980 ave tuS 1980 ave.

Action style: 1980

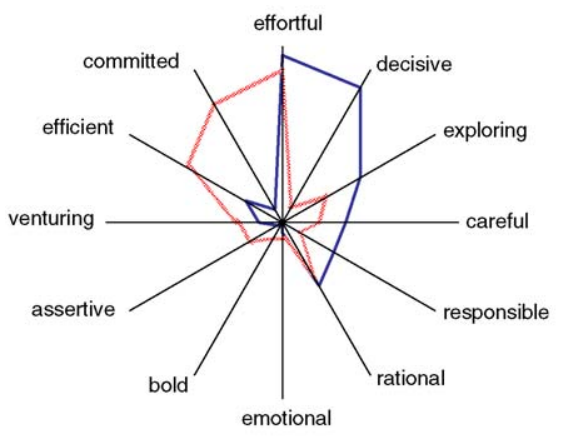

口DE 1980 ave. US 1980 ave.
Means of action: 2001

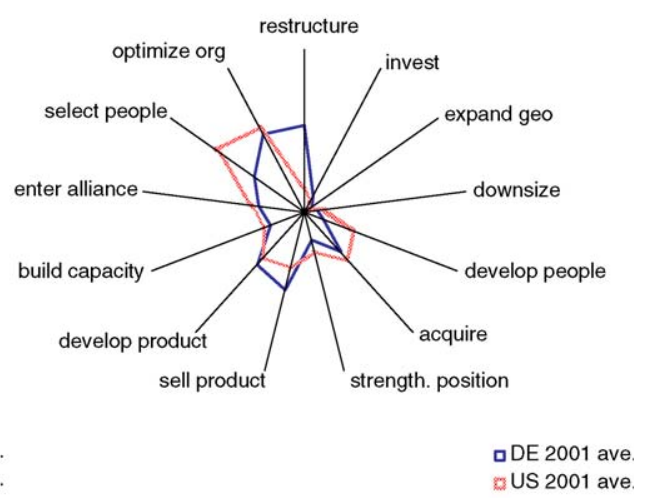

Action style: 2001

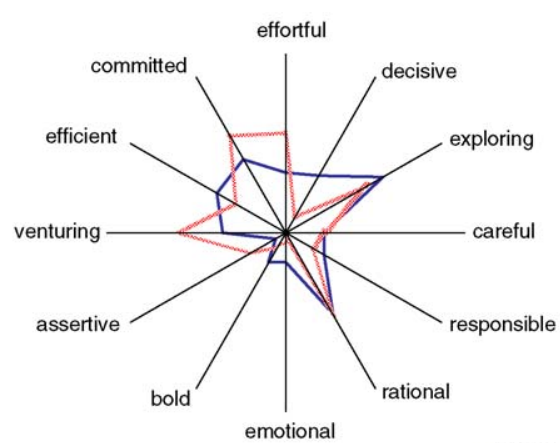

口DE 2001 ave aUS 2001 ave

Fig. 2. Repertoire profile plots for U.S. and German firm aggregates.

commitment driven and venturing, while German corporations deemed it important to present their actions as decisive but also based on careful exploration. By 2001, German firms emphasized efficiency and commitment at levels much more similar to their American counterparts, while U.S. firms talked more about exploratory ways of acting. At least on the dimensions shown above, some overall convergence between the two groups appears to have occurred from visual inspection, as the degree of overlap increased.

\subsection{Step 3: comparing similarity among toolkits}

\subsubsection{Measuring similarity and difference in cultural toolkits}

Even after quantifying the use of cultural elements by different actors, the basic challenge for systematically comparing comprehensive toolkits remains reducing the high dimensionality. How can, for example, the differences in the utilization of each of the 63 elements of corporate repertoires be converted into an assessment of overall similarity at the level of the toolkit? The answer is more straightforward when the interest is solely whether two actors' repertoires are identical or whether there is any overlap at all. However, such identical or non-overlapping cultural toolkits are a rare occurrence if the study is bounded by the analysis of a specific field. 
One option is to bypass this difficulty and ask judges familiar with both actors to rate their similarity, e.g., through the repertory grid or other methods (Mohr, 1998). Yet, this path does not make use of the information created through the systematic identification, coding and measurement process described so far.

The alternative is to use formal mathematical ways to reduce the dimensionality of the information contained in measures of element use. Various distance metrics exist for quantifying similarities and differences between any two repertoires (see, e.g., Dillon and Goldstein, 1984, for a review). There is little reason to regard some as generally superior over others. The commonly used family of Minkowski distances (e.g., Euclidean distances) does not account for differences in the variances of each comparison dimension: those categories with the greatest variance dominate the resulting metric. This can be important when, e.g., the ranges of different emphasis measures vary widely. In such cases, Mahalanobis distance measures standardize the distances on each dimension by the respective variation. Yet, although such choices can be consequential, there is often little theoretical guidance to prefer one over the other. Instead of aiming for precision, the robustness of conclusions about repertoire similarity can be enhanced by analyzing the sensitivity of findings to alternative specifications of the distance metric used.

For measurement choices regarding dyadic similarity in cultural toolkits, a more practical decision criterion is whether relative emphasis (e.g., frequency of use) should be taken into account or whether the presence or absence of a cultural element is the focal dimension. When relative emphasis is important, continuous measures are required that compare the degree of emphasis on any dimension. When emphasis is secondary, binary measures are appropriate, which only take into account the presence or absence of a cultural elements and discard information about frequency. A second decision point is whether some dimensions should be weighted more than others, for example, based on the importance attached to it by participants in the field, or the information value of a cultural element. For example, relatively rare cultural tools may be more important differentiators than those that are widely used, and some cultural expressions and symbols may be recognized identity markers.

Whatever the measure, it is useful when working with such pair-wise difference measures to identify a baseline similarity that permits comparative assessments of the type, "A is more culturally similar to B than to C." Otherwise, it is easy but futile to argue about whether a difference is big or small, important or trivial. This situation sometimes occurs in international comparative research on culture, where some emphasize how similar two countries are while others maintain that there are still many differences. As a general rule, it takes at least a triad of actors to make meaningful relative assessments. Alternatively, a temporal anchor can substitute for one actor, so that one can say that "A is more (less) culturally similar to B now than before."

\subsubsection{Scaling and representing similarity in cultural toolkits}

Once the complexity of repertoires is reduced to a single measure of similarity, standard descriptive and multivariate techniques can be used to further simplify and present the data. As these analytic tools are not specific to the cultural toolkit perspective, I will discuss them in less detail here and with a focus on analyses that lead toward mapping the use of cultural resources to positions and dynamics in the larger field. For a good general overview, see Mohr (1998).

Comparisons of cultural toolkits among individuals or collective actors are of concern to researchers with an interest in spatial variations of culture, in temporal changes, or in both. Spatial variations among actors' use of cultural material are a central part of recent debates in cultural sociology (e.g., Bourdieu, 1984 [1979]; DiMaggio, 1987; Lamont and Molnár, 2002) and of equal relevance to economic sociologists interested in classification, identity and structural 
approaches to organizational fields and markets (e.g., DiMaggio, 1986; Porac et al., 1995; White, 1992; Zuckerman, 1999). Statistical methods for spatial analysis include multi-dimensional scaling, cluster analysis and network analytic techniques, such as block modeling, all of which allow the aggregation of pair-wise similarities among many actors into a mapping of actors' relative positions in a larger field. Relative similarities are converted into locations with reference to a cultural space. For example, after submitting pair-wise similarities to a multi-dimensional scaling algorithm, two actors' position can be represented with only two coordinates in a twodimensional space. This space may also serve as an iconic map of the overall social or organizational field (Bourdieu, 1984 [1979]).

Analyses of temporal variations in cultural toolkits also use a comparative logic, but with historical rather than comparative reference points. For example, instead of creating similarity measures between pairs of actors, one can create similarity measures between the repertoire of the same actor at different points in time, or measure changes in key attributes of toolkits, such as size and heterogeneity. Studies of temporal variation in repertoires are particularly relevant to research on learning, development and cultural elaboration. Techniques range from representing change in descriptive plots of trend lines to growth curve models that model the time trend in formal ways (Rogosa et al., 1982).

More complex research questions combine spatial and temporal variation. For example, studies of international convergence (Inglehart and Baker, 2000) or the homogenization of cultural repertoires in the course of the institutionalization of a field (Suchman, 1995) require both comparative and historical reference points. The question here is one of changes in the similarity of actors' repertoires over time. Data reduction and visual presentation techniques for these questions are often combinations of spatial and temporal techniques, e.g., graphs of repeated MDS snapshots, or plots of multiple trend lines. The application of Geographical Information System (GIS) tools to the spatial and temporal mapping of culture and social fields is relatively novel and a promising direction in this regard.

\subsubsection{Illustration: similarity and difference of corporate cultural toolkits}

In the present study, I used Euclidean distances to measure how similar two companies' repertoires were. Intuitively, this distance is the length of a straight line between two points in an $n$-dimensional space. The "repertoire space" in this study is 63-dimensional, the number of elements on which two companies can be compared. The general formula for Euclidean similarity is:

$$
S=M-\sqrt{\sum_{i}\left(p_{i}-q_{i}\right)^{2}}
$$

where two points $p$ and $q$ are spatially located in $i$ dimensions. The document-level emphasis score for category $i$ provides the two point's coordinates on that dimension. $M$ is a constant used to convert distance to similarity, the observed sample maximum.

When emphasis is not of interest to the researcher, similarity metrics for binary data capture the simple presence or absence of a cultural element in both repertoires. In the present study, I used a binary measure to explore the effect of a high number of zero-scores for some companies on the conclusions derived from the Euclidean distance measure. The Euclidean distance formula treats two zeros - the absence of a cultural element in both repertoires-as more similar than a small difference on the continuous emphasis score. Yet, are two companies that do not use the same repertoire element necessarily more similar? The drawback of measures based on binary 
comparisons for this study is that they do not make full use of the emphasis information in continuous category scores. I used the Jaccard binary similarity coefficient:

$$
S=\frac{\sum c_{11}}{\sum c_{11}+\sum c_{01}+\sum c_{10}}
$$

$S$ is the number of categories $c$ present in both compared units, over the total number of categories present in at least one of the two. This measure does not count "agreements" when a category is absent from both documents (other binary measures do). Comparisons between the Jaccard and the Euclidean distance measure suggested that in this study, the zero-inflation on some categories did not affect the results in a substantive way.

\subsubsection{Illustration: graphical representation of repertoire differences}

Multi-dimensional scaling (MDS) maps the organizations in the sample onto a twodimensional space according to their dyadic similarity scores. This analysis can be used, for example, to visually examine whether groups defined by social boundaries, field positions or identities use similar cultural repertoires. To illustrate this technique, I mapped the corporations at the beginning and end of the study period. I then identified companies that operate in different segments of the industry: pharmaceutical generalists active in many therapeutic areas, pharmaceutical specialists with a narrower product portfolio, producers of generic drugs that do not develop new medicines, and biotechnology firms that specialize in research of biopharmaceuticals. In addition, I examined whether companies headquartered respectively in the United States and in Germany are mapped in proximity to each other. Fig. 3 shows the results of a metric multi-dimensional scaling analysis.

Fig. 3 visually suggests that operating in the same industry segments is not associated with cultural similarity in either year. The organizations within an industry segment are not clustered together. In 1980, German and U.S. firms are clearly separate, indicating that national affiliation is one dimension underlying differences in repertoire use. In the year 2000, nationality is no longer clearly associated with similarity in repertoire use, as German and U.S. companies are almost evenly distributed across the map. The stress value, as a measure of statistical goodness of fit, is rather high in both instances ( 0.28 and 0.32 ), which suggests that two dimensions are only a crude way to represent the more complex spatial distribution of organizations based on their dyadic similarities. Further thorough statistical analyses are thus desirable.

To illustrate the use of temporal representation techniques, I plotted the annual average similarity of three groups of dyads: pairs of two German companies, pairs of two U.S. based companies and pairs of mixed nationality. The graph shown in Fig. 4 uses lowess smoothing, a semi-parametric statistical technique that is akin to moving averages but takes into account stochastic variation. The resulting simple plot allows for a continuous assessment of similarity between the nation-based groups used in the MDS analysis. This graph can address at least two questions: whether the trend indicated in the prior scaling analysis is linear and monotonic, and whether the increased similarity between the repertoires used by U.S. and German companies is any different from the baseline of changes in similarity among domestic pairings.

Fig. 4 suggests that national differences in the use of cultural elements exist: cross-national dyads are on average less similar than either German or American domestic dyads at any point in time. Repertoires among American companies are on average more similar than among their German counterparts. The slope of the curve for cross-national dyads suggests that similarity 

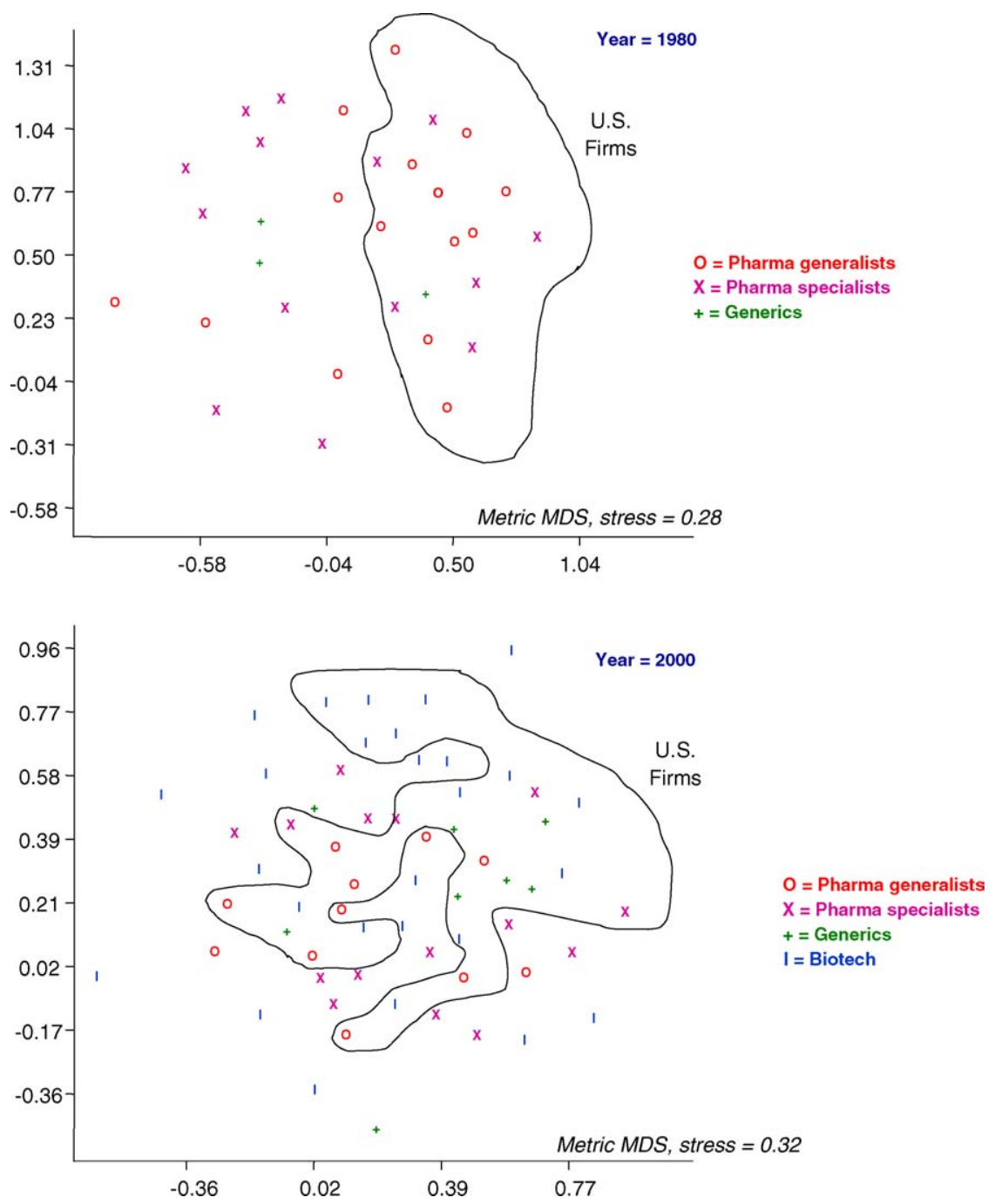

Fig. 3. Multi-dimensional scaling of organizational similarity, 1980 and 2000.

among cross-national dyads increases in the course of the 21 years studied, but not in a linear way: much of the increase occurs in the early 1990s.

\subsection{Step 4: advanced statistical analysis of correspondence between cultural and social differences}

I will only briefly touch upon some more complex statistical techniques for modeling the link between cultural similarity and social proximity. This is because I see the key challenge for quantitatively inclined analysts of culture at the toolkit level in identifying cultural elements and toolkits and in reducing the complexity of these heterogeneous sets. Once the discreteness of cultural elements has been translated into simpler measures of similarity and proximity, generic 


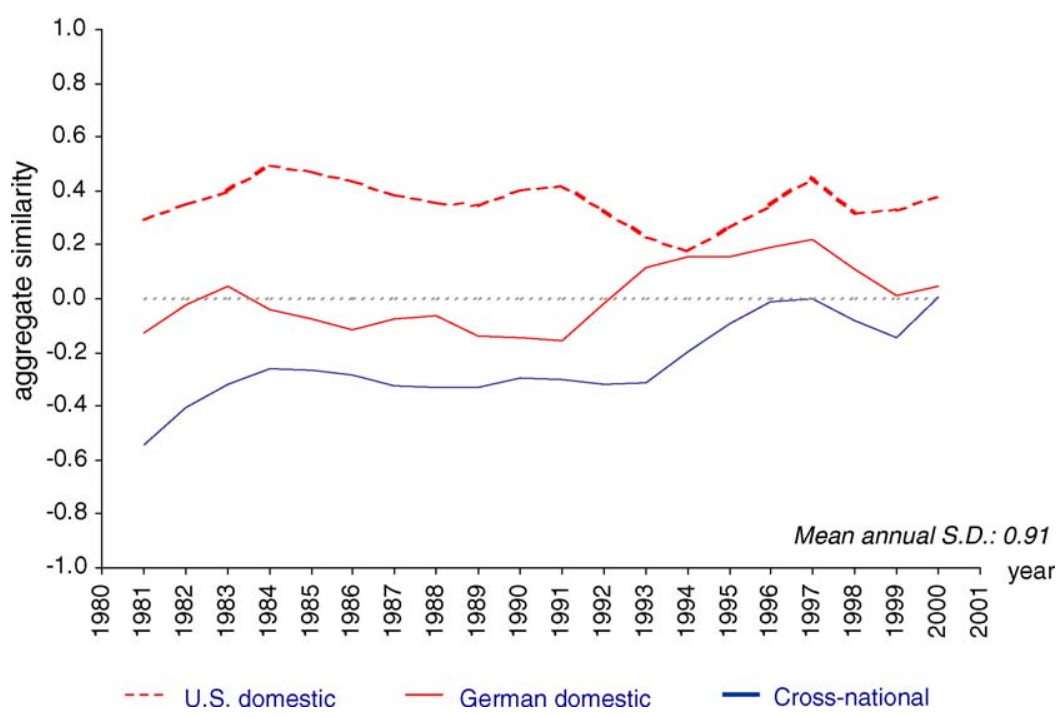

Fig. 4. Trends in repertoire similarity, 1980-2001.

methodologies for statistical analysis can be applied. Such techniques can be distinguished between those that focus on disaggregated dyadic similarities in a regression framework and another school that aims to fold positions and cultural differences into a single space.

\subsubsection{Regression analysis of correspondence using dyadic similarities}

Statistical models for dyadic data can be used to identify factors that on average affect the similarity of the cultural toolkits between any two actors in a field. Such factors may include measures of social and structural proximity in a field, such as status similarity, the strength of social relationships or structural equivalence vis-à-vis third parties, such as customers. To the extent that such factors are reliably associated with cultural similarity, one can conclude that the organization of social and cultural spaces shows some correspondence. This approach can handle large data sets and complex information, and the regression framework will be intuitively familiar to many social scientists without more specific methodological training. A drawback of the regression framework is that it only indirectly addresses the correspondence between the use of cultural elements and social positions at the field level.

Identifying systematic predictors of cultural similarity that hold across many dyadic comparisons requires the statistical analysis of a matrix of all possible dyads. As each organization is then present in multiple dyads, non-independence of dyadic analysis units is a concern. No perfect solution to this problem exists, but several corrections can be used. Noninterdependence can be addressed by using a Quadratic Assignment Procedure (QAP), in which random permutations of rows and columns in the network matrix allow the estimation of robust regression parameters and significance tests (Borgatti et al., 2002). QAP regression is, however, limited in that it does not allow certain structures of the input data that would be desirable for some research questions. Spatial regression models pose similar limitations. Fixed and random effects regression models are other alternatives to address the issue of non-independence. For example, in "Least Squares with Dummy Variables" (LSDV) regression models, fixed effects dummies are included for each unit (Hannan and Young, 1977; Mizruchi, 1989). Again, analytic 
limitations arise, in this case regarding the difficulty of including constant covariates in longitudinal designs. Generalized hierarchical and mixed model regression allows the inclusion of random effects and pose fewer constraints regarding data structure and covariates (Bryk and Raudenbusch, 2003). These models, however, require quite careful specification to yield robust results (Bijleveld and Van der Kamp, 1998).

\subsubsection{Statistical correspondence analysis using spatial positions}

While techniques for dyadic data use a matrix of similarity measures between actors as the dependent variable in a regression equation, an alternative set of approaches analyzes a data matrix in which cultural positions are one axis and social positions or actors are on the other. This approach deviates both methodologically and "in spirit" from the regression approach described above in that it aims to identify underlying dimensions that organize both cultural and social space. Instead of using the apparatus of statistical prediction, it uses the mathematical apparatus of reduction of dimensionality (e.g., eigenvectors) at a more advanced level than the more basic data reduction techniques described in the previous steps of analysis. These approaches are attractive because of their close correspondence with the relational theoretical underpinnings of field and practice theories. A drawback is their limitations in working with large complex information sets, such as expansive toolkits and many actors. The main variants of this school of analysis are Bourdieu's correspondence analysis (Bourdieu and Waquant, 1992 [1988]) and Galois lattice analysis (Breiger, 2000). Both are extensively reviewed and developed by Breiger (2000) and I refer the interested reader to this article.

\section{Conclusion}

The goal of this article was to expand the toolkit of cultural researchers by discussing and illustrating some approaches to analyzing cultural toolkits. The analytic strategy and specific techniques I described are particularly suitable for analyzing cultural toolkits at the level of the toolkit and in relation to the larger field in which actors are located. This type of analysis is relatively rare, as most research currently focuses on selective elements or deep cultural structures. Yet, it is exactly the ability to think in comprehensive toolkits and registers that makes the perspective of culture as repertoire unique. The availability of methodological tools for solving researchers' practical problems in implementing this perspective are key to advancing the study of cultural resources, at least according to that very theory.

The main contribution of this article is a step-by-step process for reducing the complexity and information load that is created by the initial decision to study more comprehensive sets of cultural elements. This reduction goes hand in hand with increasingly quantitative techniques, moving from purely qualitative semiotic analysis to highly abstract statistics. In an effort to counter the corresponding increase of abstraction, I placed great emphasis on visual representation as a way to retain an intuitive understanding of the data. The idea is not at all to suggest that qualitative and interpretive processes of data reduction are inadequate. Rather, those tools are part of the standard repertoire of many cultural analysts and hence, in order to expand the register of techniques in the field of cultural approaches to markets and organizations, I focused on less well-known methods. The less quantitatively inclined researcher should note that he or she can stop at any point in the process and of course can recombine elements of the overall strategy. There is no necessity in moving, for example, from the representation of individual repertoire profiles to multi-dimensional scaling, and from there to regression analyses. 
My hope is also that the toolkit presented here, and the illustrations with aspects of corporate cultural repertoires, will be particularly useful for researchers that use cultural approaches in the study of markets and organizational fields. The notion of embedded agency that is at the heart of the cultural toolkit approach to action for sure is highly relevant to studies of collective and normatively rational actors, such as modern corporations. And the concern with sense-making and cultural expression offers a counter-weight to the current spotlight on information flows and asymmetries that often sidestep the problem of interpretation and meaning.

\section{References}

Abbott, Andrew D., 1995. Sequence analysis. Annual Review of Sociology 21, 93-113.

Abolafia, Mitchel Y., Kilduff, Martin, 1988. Enacting market crisis: the social construction of a speculative bubble. Administrative Science Quarterly 33, 177-193.

Barthes, Roland, 1967 [1964]. Elements of Semiology. Jonathan Cape, London.

Bearman, Peter S., Stovel, Katherine, 2000. Becoming a Nazi: a model for narrative networks. Poetics 27, 69-90.

Bergson, Henri., 1946 [1903]. The Creative Mind: An Introduction to Metaphysics. Kensington, New York.

Biggart, Nicole Woolsey, Guillén, Mauro F., 1999. Developing difference: social organization and the rise of the auto industries of South Korea, Taiwan, Spain, and Argentina. American Sociological Review 64, 722-747.

Bijleveld, Catrien C.J.H., Van der Kamp, Leo J.T., 1998. Longitudinal Data Analysis: Designs, Models and Methods. Sage, Thousand Oaks, CA.

Borgatti, Steven P., Everett, M.G., Freeman, Linton C., 2002. Ucinet 6 for Windows: software for social network analysis. Analytic Technologies, Harvard.

Bourdieu, Pierre., 1984 [1979]. Distinction: A Social Critique of the Judgment of Taste. Harvard University Press, Cambridge, MA.

Bourdieu, Pierre, 1990 [1980]. The Logic of Practice. Polity Press, Cambridge, UK.

Bourdieu, P., 1993. Some properties of fields. In: Sociology in Question, Sage, London, pp. 72-77.

Bourdieu, Pierre, Waquant, Loic J.D., 1992 [1988]. An Invitation to Reflexive Sociology. University of Chicago Press, Chicago, IL.

Breiger, Ronald L., 2000. A tool kit for practice theory. Poetics 27, 91-115.

Bryk, Anthony S., Raudenbusch, Stephen.W., 2003. Hierarchical Linear Models. Sage, Newbury Park, CA.

Carley, Kathleen, 1993. Coding choices for textual analysis: a comparison of content analysis and map analysis. Sociological Methodology 23, 75-126.

Carley, K., 1997. Extracting team mental models through textual analysis. Journal of Organizational Behavior 18, 533558.

Chandler, Daniel, n.d. Semiotics for beginners. Online Book, University of Aberdeen, UK, http://www.aber.ac.uk/media/ Documents/S4B/semiotic.html.

Chen, Ming-Jer, 1996. Competitor analysis and interfirm rivalry: toward a theoretical integration. Academy of Management Journal 21, 100-134.

Collins, Randall, 2004. Interaction Ritual Chains. Princeton University Press, Princeton, NJ.

Czarniawska, Barbara., 1998. A Narrative Approach to Organizational Studies. Sage, Thousand Oaks, CA.

Dess, Gregory G., Beard, D.W., 1984. Dimensions of organizational task environments. Administrative Science Quarterly 29, 52-73.

Dewey, John, 1939. "Theory of valuation.” International Encyclopedia of Unified Science II.

Dillon, W.R., Goldstein, M., 1984. Multivariate Analysis: Method and Applications. Wiley, New York.

DiMaggio, Paul J., 1986. Structural analysis of organizational fields: a blockmodel approach. Research in Organizational Behavior 8, 335-370.

DiMaggio, Paul J., 1987. Classification in art. American Sociological Review 52, 440-455.

DiMaggio, Paul J., Powell, Walter W., 1983. The iron cage revisited: institutional isomorphism and collective rationality in organizational fields. American Sociological Review 48, 147-160.

Dobbin, Frank, 1994. Forging Industrial Policy: The United States, Britain, and France in the Railway Age. Cambridge University Press, London, UK.

Dutton, Jane E., Jackson, S.E., 1987. Categorizing strategic issues: links to organizational action. Academy of Management Review 12, 76-90.

Eco, Umberto, 1976. A Theory of Semiotics. Indiana University Press, Bloomington, IN. 
Eliasoph, Nina, Lichterman, Paul, 2003. Culture in interaction. American Journal of Sociology 108, $735-794$.

Evans, William, 1996. Computer-supported content analysis. Social Science Computer Review 14, $169-179$.

Feldman, Martha S., 1995. Strategies for Interpreting Qualitative Data. Sage, Thousand Oaks, CA.

Firebaugh, Glenn, 1997. Analyzing Repeated Surveys. Sage, Thousand Oaks, CA.

Fiss, Peer C., Hirsch, Paul, 2005. The discourse of globalization: framing and sensemaking of an emerging concept. American Sociological Review 70, 25-52.

Fiss, Peer C., Zajac, Edward J., 2004. The diffusion of ideas over contested terrain: the (non)adoption of a shareholder value orientation among German firms. Administrative Science Quarterly 49, 501-534.

Fligstein, Neil J., 2001. Social skill and the theory of fields. Sociological Theory 19, 105-125.

Foucault, Michel, 1972. The Archeology of Knowledge. Routledge, London.

Franzosi, Roberto, 1998. Narrative analysis-or why (and how) sociologists should be interested in narrative. Annual Review of Sociology 24, 517-554.

Gartman, David, 2002. Bourdieu's theory of cultural change: explication, application, critique. Sociological Theory 20 , 255-277.

Giddens, Anthony, 1984. The Constitution of Society: Outline of the Theory of Structuration. University of California Press, Berkeley, CA.

Gioia, Dennis A., Thomas, James B., 1996. Identity, image, and issue interpretation: sensemaking during strategic change in academia. Administrative Science Quarterly 41, 370-403.

Goffman, Erving, 1974. Frame Analysis. Harper \& Row, New York.

Greimas, Algirdas, 1987. On Meaning: Selected Writings in Semiotic Theory. Frances Pinter, London.

Guillén, Mauro F., 1994. Models of Management: Work, Authority and Organization in a Comparative Perspective. University of Chicago Press, Chicago, IL.

Hannan, Michael T., Young, Alice A., 1977. Estimation in panel models: results on pooling cross-sections and time series. In: Heise, David R. (Ed.), Sociological Methodology. Jossey-Bass, San Francisco, pp. 52-83.

Husserl, Edmund, 1962 [1913]. Ideas: A General Introduction to Pure Phenomenology. Collier Macmillan, New York.

Inglehart, Ronald, Baker, Wayne E., 2000. Modernization, cultural change, and the persistence of traditional values. American Sociological Review 65, 19-51.

James, William, 1890. The Principles of Psychology. Dover, New York.

Krippendorff, Klaus, 2003. Content Analysis: An Introduction to its Methodology. Sage, Beverly Hills, CA.

Lamont, Michèle, Molnár, Virág, 2002. The study of boundaries in the social sciences. Annual Review of Sociology 28, 167-195.

Lamont, Michèle, Thévenot, Laurent (Eds.), 2000. Rethinking Comparative Cultural Sociology. Cambridge University Press, New York.

Lasswell, Harold D., Leiters, Nathan, 1949. Language of Politics: Studies in Quantitative Semantics. George W Steward, New York.

Levi-Strauss, Claude, 1966 [1962]. The Savage Mind. University of Chicago Press, Chicago, IL.

Levi-Strauss, Claude, 1974. Structural Anthropology. Basic Books, New York.

Miller, Danny, Chen, Ming-Jer, 1996. The simplicity of competitive repertoires: an empirical analysis. Strategic Management Journal 17, 419-439.

Mizruchi, Mark S., 1989. Similarity of political behavior among large American corporations. American Journal of Sociology 95, 401-424.

Mohr, John W., 1998. Measuring meaning structures. Annual Review of Sociology 24, 345-370.

Namenwirth, J. Zvi, Weber, Robert P., 1987. Dynamics of Culture. Allen \& Unwin, Winchester, MA.

Peirce, Charles Sanders, 1955 [1898]. Logic as semiotic: the theory of signs. In: Buchler, Justus (Ed.), Philosophical Writings of Peirce. Dover, New York, pp. 98-119.

Peterson, Richard A., Kern, Roger M., 1996. Changing highbrow taste: from snob to omnivore. American Sociological Review 61, 900-907.

Podolny, Joel M., Hill-Popper, Marya, 2004. Hedonic and transcendent conceptions of value. Industrial and Corporate Change 13, 91-116.

Porac, Joseph F., Rosa, Jose Antonio, 1996. Rivalry, industry models, and the cognitive embeddedness of the comparable firm. Advances in Strategic Management 13, 363-388.

Porac, Joseph F., Thomas, Howard, Wilson, Fiona, Paton, Douglas, Kanfer, Alaina, 1995. Rivalry and the industry model of Scottish knitwear producers. Administrative Science Quarterly 40, 203-227.

Porac, Joseph F., Wade, James B., Pollock, Timothy G., 1999. Industry categories and the politics of the comparable firm in CEO compensation. Administrative Science Quarterly 44, 112-144.

Porter, Michael E., 1980. Competitive Strategy. Free Press, New York. 
Putnam, Linda L., Fairhurst, Gail T., 2000. Discourse analysis in organizations: issues and concerns. In: Jablin, Fredric M., Putnam, Linda L. (Eds.), The New Handbook of Organizational Communication. Sage, Thousand Oaks, CA, pp. 78-136.

Roberts, Carl W., 2000. A conceptual framework for quantitative text analysis. Quality \& Quantity 34, $259-274$.

Rogosa, David R., Brandt, David, Zimowski, Michele, 1982. A growth curve approach to the measurement of change. Psychological Bulletin 90, 726-748.

Saussure, Ferdinand de, 1959 [1915]. Course in General Linguistics. McGraw-Hill, New York.

Schatzki, Theodore R., Knorr-Cetina, Karin, Von Savigny, Eike (Eds.), 2001. The Practice Turn in Contemporary Theory. Routledge, New York.

Scott, W. Richard, Meyer, John W., 1983. The organization of societal actors. In: Meyer, John W., Scott, W. Richard (Eds.), Organizational Environments: Ritual and Rationality. Sage, Beverley Hills, CA, pp. 129-153.

Scott, W. Richard, Ruef, Martin, Mendel, Peter, Caronna, Carol, 2000. Institutional Change and Healthcare Organizations: From Professional Dominance to Managed Care. University of Chicago Press, Chicago.

Somers, Margaret R., 1994. The narrative constitution of identity: a relational and network approach. Theory and Society 23, 605-649.

Suchman, Mark C., 1995. Localism and globalism in institutional analysis: the emergence of contractual norms in venture finance. In: Scott, W. Richard, Christensen, Soren (Eds.), The Institutional Construction of Organizations: International and Longitudinal Studies. Sage, Thousand Oaks, CA, pp. 39-63.

Sutcliffe, Kathleen M., Huber, George P., 1998. Firm and industry as determinants of executive perceptions of the environment. Strategic Management Journal 19, 793-807.

Swidler, Ann, 1986. Culture in action: symbols and strategies. American Sociological Review 51, $273-286$.

Swidler, Ann, 2001a. Talk of Love: How Culture Matters. University of Chicago Press, Chicago, IL.

Swidler, Ann, 2001b. Transcript of interview by Kelly Besecke and Lyn Macgregor. University of Wisconsin at Madison.

Swidler, A., 2002. Cultural repertoires and cultural logics: can they be reconciled? Comparative and Historical Sociology 14, 1-6.

Thomas, James B., Clark, Shawn M., Gioia, Dennis A., 1993. Strategic sensemaking and organizational performance: linkages among scanning, interpretation, action and outcomes. Academy of Management Journal 36, $239-270$.

Thornton, Patricia H., Ocasio, William, 1999. Institutional logics and the historical contingency of power in organizations: executive succession in the higher education publishing industry, 1958-1990. American Journal of Sociology $105,801-843$.

Wade, James B., Porac, Joseph F., Pollock, Timothy G., 1997. Worth, words, and the justification of executive pay. Journal of Organizational Behavior 18, 641-664.

Weick, Karl E., 1979. The Social Psychology of Organizing. Random House, New York.

Weick, Karl E., 1995. Sensemaking in Organizations. Sage, Thousand Oaks.

Weick, Karl E., 1996. Drop your tools: an allegory for organizational studies. Administrative Science Quarterly 41, 301313.

West, Mark D. (Ed.), 2001. Theory, Method, and Practice of Computer Content Analysis. Ablex, Westport, CT.

White, Harrison C., 1992. Identity and Control. Princeton University Press, Princeton, NJ.

White, Harrison C., 2000. Modeling discourse in and around markets. Poetics 27, 117-133.

Wiley, Norbert, 1988. The micro-macro problem in social theory. Sociological Theory 6, 254-261.

Zerubavel, Eviatar, 2003. Time Maps: Collective Memory and the Social Shape of the Past. University of Chicago Press, Chicago, IL.

Zuckerman, Ezra W., 1999. The categorical imperative: securities analysts and the illegitimacy discount. American Journal of Sociology 104, 1398-1438.

Klaus Weber is an Assistant Professor of Management and Organization at the Kellogg School of Management, Northwestern University. His research examines the cultural-cognitive and institutional underpinnings of modern corporations and markets. His particular interest is in the relation between pragmatic local sensemaking and macrolevel factors, such as institutions, culture, social structures and social movements. The article in this issue draws on research about pharmaceutical companies' changing use of cultural resources in an international organizational field. In addition, he is currently conducting research on the mechanisms through which social movements affect organizational technology trajectories, and on the changing repertoires of evaluation that securities analysts deploy to price biotechnology companies. 